\title{
Making Inferences Using Incidentally Collected Data
}

Jonathan Mellon- Nuffield College, University of Oxford

This chapter discusses the use of large quantities of incidentally collected data (ICD) to make inferences about politics. This type of data is sometimes referred to as "big data". However , I avoid using that term here because big data has at least six commonly used definitions that contradict each other in various ways (Monroe, 2012; Ward \& Barker, 2013). I define ICD as data that was created or collected primarily for a purpose other than analysis. Within this broad definition, this chapter focuses particularly on data generated through user interactions with websites. While ICD has been around for at least half a century (see for instance Hollway and Mellon (2014) analyzing 1973 U.S. State Department cables), the Internet greatly expanded the availability and reduced the cost of ICD. Examples of ICD include data on Internet searches, social media data, and user data from civic platforms.

This chapter briefly explains some sources and uses of ICD and then discusses some of the potential issues of analysis and interpretation that arise when using ICD.

\section{Data Sources}

This section outlines some commonly used sources of ICD for elections and public opinion research.

\section{Internet Search Data}

One of the most commonly used forms of ICD is Internet search data, particularly from Google Trends. Google Trends provides aggregated time series counting the number of searches for a particular search term within a specified geographic area. The time series are available daily or weekly. Google data has been used in public opinion research to study issue salience (Mellon, 2013a, 2013b; Ripberger, 2011; Scharkow \& Vogelgesang, 2011; Weeks \& Southwell, 2010; Wilde \& Pope, 2012), interest in candidates (Ellis, Swearingen, \& Ripberger, 2011), and racist attitudes (StephensDavidowitz, 2012), as well as to forecast elections (Graefe \& Armstrong, 2012)

\section{Social Media Data}

Another commonly used form of ICD in analysis is social media data, particularly from Twitter and Facebook. Twitter is probably the most studied social media platform due to its relatively open API and data agreements with research institutions (Boyd \& Crawford, 2011).

Twitter data has been used for research questions including election forecasting (Choy, Cheong, Laik, \& Shung, 2012; Digrazia, McKelvey, Bollen, \& Rojas, 2013; Jensen \& Anstead, 2013; MarchettiBowick \& Chambers, 2012; McKelvey, DiGrazia, \& Rojas, 2014; O’Connor, Balasubramanyan, Routledge, \& Smith, 2010; Sang \& Bos, 2012; Tumasjan, Sprenger, Sandner, \& Welpe, 2010), studying the diffusion of political messages (Larsson \& Moe, 2011), analyzing the interactions and behavior of elites (Adi, Erickson, \& Lilleker, 2013; Barbera, 2014; Bruns \& Highfield, 2013; Cook, 2015) and studying political polarization (Gruzd, 2012).

\footnotetext{
${ }^{1}$ An overview of Twitter's APIs can be seen at https://dev.twitter.com/overview/api.
} 
Facebook data has seen much more limited use in public opinion research, seemingly because it lacks an open API, although there are a number of studies that have made use of Facebook data to study issue engagement (Vraga, Anderson, Kotcher, \& Maibach, 2015), turnout (Bond et al., 2012), and deliberation (Camaj \& Santana, 2015).

\section{Civic Platforms}

Another source of ICD is from civic platforms that are designed to facilitate civic or political participation. Researchers have collected data from online petitioning websites (Mellon, Sjoberg, \& Peixoto, 2016a), platforms for reporting problems to local government (Sjoberg, Mellon, \& Peixoto, 2015) and Voter advice applications (Garzia \& Marschall, 2012; Wall, Krouwel, \& Vitiello, 2014). These sources tend to be used to study the forms of political behavior that the platform facilitates rather than studying public opinion and behavior more generally. Data from civic platforms tends to be obtained either through direct agreements with the provider or accessing the data through an API. Data can also be obtained by automatically scraping data from the website, but researchers should consider whether this is allowable under the website's terms and conditions and whether doing so will violate any ethical considerations such as user privacy.

\section{Five Logics of Inference}

The aim of much of public opinion research is to make inferences about populations. For instance, political scientists conduct surveys to understand the proportion of voters supporting a particular candidate, run regressions to understand the relationship between anti-immigrant sentiment and authoritarianism within a population, or use content analysis to understand media bias in election campaigns.

By far the most common logic of inference in these cases is representativeness: that we can make inferences about a population because the sample we use is representative of that population. The simplest version is when a sample is conducted through a simple random sample with a $100 \%$ response rate. In this case, no adjustments are necessary to make the sample representative and estimates made using such a sample converge to the true values as the sample size increases (assuming the instruments are unbiased).

Inference using ICD is rarely this simple. There are few, if any, examples where ICD can be demonstrated to be representative of the general population in as simple a manner (although it may be representative of certain subpopulations).

While most papers using ICD do not explicitly state their logic of inference, nearly all of them rely on one or more of five approaches: representativeness, limiting inference to the sampled population, invariant mechanisms, validation, or assumed validity.

\section{Representativeness}

The first method of inference that research on ICD uses is representativeness. ICD are rarely a simple random sample of the population, so additional steps are required before inferences can be made. As with survey data, when an initial sample is not representative, it is sometimes possible to achieve representativeness using weighting techniques, however, this requires the assumption that the sample is representative within the weighting strata. In general, it appears that Facebook users tend to be more demographically and politically representative of the general population than Twitter users (Mellon \& Prosser, 2016), but that both groups would take considerable adjustment to make them 
representative of the general population. While studies usually do not assume that ICD are a sample of the general population of a country, many studies do try to make inferences on the basis that a sample is representative of a subpopulation.

\section{Only inferring about the Sampled Population}

The second approach to inference that studies using ICD use is to limit inferences to the population from which the sample was drawn or even the sample itself (which is common if the researcher has the complete dataset). The drawback of this approach to inference is that the study can only claim to tell us about the population that was sampled. This can potentially make conclusions less wideranging, but can also be useful if the sampled population is particularly influential or politically relevant.

\section{Defining the Relevant Population}

In standard social science data collection, the sampling procedure will generally reflect the analysis to be conducted. If a research question is about countries, data will be collected at the country level and if a question is about the behavior of individual voters, then data will be sampled at the individual level.

With ICD, the data will generally be organized at whatever level was most useful for the original purpose. Often this is in the form of event logs, which take an event as the unit of analysis. However, making inferences about the universe of events will often not be the aim of a political scientist.

In public opinion research and elections research, we generally treat the individual as the fundamental unit of analysis. That is, we want to know something about the average individual in a population. In most survey research, we are interested in knowing something about the distribution of a variable across individuals. In the case of media analysis, we are usually ultimately interested in understanding the distribution of exposure to possible influencers across individuals e.g. how much pro-Labour media is a typical voter exposed to?

These different populations are exemplified by Twitter. If we are, for instance, interested in using Twitter data in the run up to a UK election, we could be interested in making inferences about any of the following (even before we consider making inferences beyond Twitter):

1. UK tweets

2. The consumption of Twitter content in the UK

3. The behaviour of UK twitter users

These choices are not trivial because of the highly skewed nature of Twitter. The median twitter account has just one follower (Bruner, 2013).

The first of these options is often the default way in which researchers receive Twitter data: a chronological stream of tweets written that match certain criteria (such as location, time and topic), gathered by storing tweets matching a certain criteria in the streaming API for a certain time period. However, it is not immediately clear why we should care about tweets as a population to make inferences about. If we think that Twitter is politically relevant because it is an important source of campaign information, then we should be focused on the second option: what Twitter users consume and if we are interested in Twitter as a source of data on the political behavior of individuals, then we should be interested in the third option. A stream of tweets is essentially a measure of individual behavior (tweeting) weighted proportionally to the level of activity of each individual. However, many articles using Twitter data (Caldarelli et al., 2014; Christensen, 2013; A. Jungherr, Jurgens, \& 
Schoen, 2011; Andreas Jungherr, 2014; Raynauld \& Greenberg, 2014) take it is as given that the content of Twitter as a whole is the most relevant analysis frame.

The second option (the consumption of Twitter content in the UK) is most useful for research looking at Twitter as a medium for media consumption. Obtaining a representative sample of what content is consumed on Twitter is possible using weighting. To do this, a researcher simply needs to capture a stream of tweets fitting particular criteria and then subsequently reweight or resample according to the number of followers the creator of each tweet has. This means that a tweet that was likely seen by 10,000 followers is weighted 500 times as highly as a tweet seen that was likely seen by 20 followers. While there are some simplifying assumptions ${ }^{2}$ in this process, it will create a collection of tweets that much more closely resembles what people see on Twitter. If we are interested in Twitter as a source of information, then this is the most relevant universe.

The difference between what is consumed and what is tweeted is likely to be important. While twitter users as a whole are numerous enough that they span many sections of society, popular twitter users tend to be more reflective of existing sources of political influence: e.g. celebrities, media figures, academics and political figures. Focusing on everything that is tweeted would be likely to give the impression that Twitter consumption looks less like traditional media than is actually the case.

The third potential population of interest is Twitter users themselves or a particular subset of the users. Samples of Twitter users can be obtained in a number of ways. It is possible to scrape a random sample of users from the Twitter API by randomly sampling ID numbers from a uniform distribution (Bruner, 2013), as user IDs are assigned more or less sequentially over time. As of 2013, around 63\% of randomly chosen ID numbers resolved to a Twitter user. The downside of this approach is that it is not possible to filter users by particular criteria, so researchers would have to sample the whole of Twitter and then discard all non-relevant users.

Alternatively a researcher could obtain a representative sample of active users (i.e. users who tweeted at least once in a time period), by collecting all tweets matching particular criteria (e.g. in the UK and mentioning political terms). The researcher can then use the Twitter search API to collect the full tweeting behavior of these users in this time period. This approach is relatively rare in the literature, although Boyadjian and Neihouser (2014) do demonstrate how to collect a panel of Twitter users.

Another approach that has been taken is to define a core set of political twitter users such as politicians from other sources. Politically interested users can then be further identified by looking at the followers of these core political users (Barbera, 2014). Similarly other studies have looked at all users who tweeted using a particular hashtag (Larsson \& Moe, 2011).

This discussion is not to say that researchers should never use a stream of tweets as their dataset, simply that they should have good and articulable reasons for doing so that match their stated research questions.

The distinction between the different populations of inference applies beyond the case of Twitter. For instance Mellon, Sjoberg, and Peixoto (2016b) use a sample of change.org petitions that were sampled from a random sample of users' signatures. Because a petition with many signatures is therefore more likely to be sampled it was necessary for them to correct for the sampling process using weighting in

\footnotetext{
${ }^{2}$ In particular, we assume that Twitter all followers are equally likely to read a tweet and that the follower count attached to a tweet that matches a certain criterion (such as originating from the UK) is representative of the number of UK followers.
} 
order to even make the sample representative of the population of petitions on change.org (which was the population they made inferences about).

Other examples of ICD being used to make inferences about a population other than the general population include Gibson and Ward's (2003) analysis of Australian party websites using automated content analysis. At least at that period, this could be seen as a reasonably representative sample of how the parties were using the Internet, and the behavior of parties online was the research question. If the aim had been to make an inference about party behavior in general, the inference would have required more assumptions or validation. Similar approaches have looked at elections in Norway (Enli \& Skogerbø, 2013) and other Australian elections (Bruns \& Highfield, 2013).

\section{Invariant mechanisms}

Another form of inference that is sometimes used with ICD is to argue that even though the sample is unrepresentative, the social mechanisms that the authors are testing are not likely to be affected by the sample's unrepresentativeness. This is essentially the same logic that governs external validity in laboratory experiments. As with experiments, the extent to which this is a convincing argument will vary dramatically across studies. This logic of inference is rarely convincing when trying to get exact point estimates of a proportion (e.g. the proportion of voters who will vote for the Democrats), but can be more convincing when trying to understand how two variables will be correlated (e.g. whether consumption of left-wing media content correlates with voting democrat).

One example of this logic is a 61 million person get-out-the-vote experiment that was run on Facebook users by showing them a message about their friends' voting (Bond et al., 2012). Given the size of Facebook this is interesting in its own right, but it is also plausible that such subtle social nudges are influential outside of Facebook, helping to justify the wider conclusions that the authors drew.

In another example Mellon et al. (2016b) examine predictors of petition success on the change.org platform. They argue that the mechanisms tested are sufficiently broad (level of mobilization, institutional support and regime type) that they are likely to apply to settings beyond the change.org platform. While the analysis itself makes inferences about petitions on the platform, the conclusions are drawn more widely.

In another example Reddit data was used to examine the types of arguments that are most convincing to other people (Tan, Niculae, Danescu-Niculescu-Mizil, \& Lee, 2016). While the data is specific to the Reddit platform, the authors explicitly make wider claims about the mechanisms behind persuasion. In this case, the generalizability of the findings is more difficult to assess. The data the paper uses is based on the ChangeMyView Reddit forum where users specifically ask for people to try and change their minds. It is therefore unclear whether data from this setting is relevant to opinion change more generally.

In each of these cases, the mechanisms are argued to be sufficiently similar in the available ICD that wider conclusions can be drawn.

\section{Validation of Proxies}

Another form of logic that is used to make inferences about a population on the basis of incidentally collected data is to focus on validation. In this case, it is considered sufficient to use the incidentally 
collected data to measure public opinion if we can be confident that there is a strong relationship between the underlying variable in the population and a particular measurement using ICD.

An example of the validation logic comes from work using Google Trends. Mellon (2013a) outlines a three step procedure for determining the extent to which a Google Trends time series can be considered a valid proxy for the salience of a particular issue: face validity, content validity and criterion validity.

Face validity simply refers to whether or not a Google Trends term initially looks plausible as a proxy for a given variable. For instance, the search term "council housing" seems initially plausible as a measure of the issue salience of housing in the UK.

Content validity goes a step further and examines the actual search terms that were used within searches that make up the trend for a keyword. For instance, are Google Trends for "jobs" about searches for employment or the new Steve Jobs biopic? Google Trends allows the top terms for a trend to be downloaded and examined. Problematic terms can then be iteratively removed, to leave only relevant searches.

Criterion validity refers to the extent to which a measure can be shown to correlate with an existing gold standard measure. Given the widespread concerns about traditional data collection techniques such as polling data (Mellon, 2013b; Mokrzycki, Keeter, \& Kennedy, 2009; Sturgis et al., 2016), it is doubtful whether we truly have a gold standard for many public opinion measures, but traditional techniques at least have a set of established standards for assessing their likely quality and have unambiguous tests of their accuracy around elections.

When applying these steps to Google Trends series in the US, just 5 out of 20 trends that had face validity were shown to possess both content validity and criterion validity (Mellon, 2013a). A similarly low validation rate was seen in Spain (5 out of 12) and the United Kingdom (14 out of 39) (Mellon, 2013b). In none of the three countries was an initially plausible Google Trends series more likely to turn out to be valid than not. While these steps are designed around using Internet search data, many other sources of ICD could potentially benefit from similar steps of validation.

Another part of the literature which has focused heavily on external validation is forecasting. These papers tend to use tweets as the unit of analysis and generally focuses on mentions of different candidates. While several papers have claimed success in this process (Choy et al., 2012; Digrazia et al., 2013; Marchetti-Bowick \& Chambers, 2012; McKelvey et al., 2014; O’Connor et al., 2010; Sang $\&$ Bos, 2012; Tumasjan et al., 2010), subsequent research has suggested that these papers succeeded only due to arbitrary decisions (Gayo-Avello, 2012) and that when these methods are applied to elections other than the one where success is claimed they perform no better than chance (GayoAvello, Metaxas, \& Mustafaraj, 2011; Metaxas, Mustafaraj, \& Gayo-Avello, 2011). Additionally, a pre-registered Twitter forecast of the 2015 UK election did not replicate the success of retrospective "forecasts" (Burnap, Gibson, Sloan, Southern, \& Williams, 2015). ${ }^{3}$

This performance is perhaps not that surprising, given that: 1) almost all papers on this topic use tweet counts, which (as noted above) neither track twitter user behavior nor what twitter users are exposed to and 2) twitter users are highly unrepresentative of the general public (Mellon \& Prosser, 2016; Vaccari et al., 2013).

\footnotetext{
${ }^{3}$ It should be noted that all the forecasts in the 2015 UK forecasting symposium performed poorly (Fisher \& Lewis-Beck, 2015), so Twitter forecasting was certainly not the only method called into question.
} 


\section{Assumed Validity of Proxies}

Other studies do not explicitly use any of the preceding logics of inference and instead rely solely on face validity to make inferences from ICD to the general population. This approach has been taken in a high proportion of public opinion research using Google Trends (Anderegg \& Goldsmith, 2014; Granka, 2010; Koehler-Derrick, 2013; Ragas \& Tran, 2013; Stephens-Davidowitz, 2012; Wilde \& Pope, 2012). In some cases this is unavoidable because there is very little data to validate against (Koehler-Derrick, 2013) but the reliability of any findings that use Google Trends without validation is unknown and likely to be low.

A good example of a case where Google Trends may track the wrong population is an International Organization article looking at Google searches for the World Trade Organization when disputes are taking place (Pelc, 2013). While this suggests that there is a robust effect on search volume, it is not possible to tell who is doing the searching and whether this represents a narrow or wide concern about the World Trade Organization. Since the search trends are normalized, the level of searching may represent an increase in concern from $0.1 \%$ to $0.3 \%$ of the population or $25 \%$ to $75 \%$ of the population. It is also plausible that directly affected businesses, government employees, and journalists might increase their searches for the World Trade Organization, and these searches would not be distinguishable from those of the general public. Finally, it is not clear whether merely searching for the WTO is actually an indicator of policy preferences about the WTO.

In another case, researchers suggested that attention to climate change had declined on the basis of falling searches for climate change related terms (Anderegg \& Goldsmith, 2014), but this was directly contradicted by the survey evidence that showed concern rising slightly over the same period (Tepper, 2014). This example highlights a potential danger of ICD analysis. Given ICD's ease of collection and low cost, researchers may be tempted to not consult traditional data sources that may be more suited to answering a particular question or even stop collecting some traditional data in lieu of ICD. As the examples above show, this would be a serious mistake, as ICD is often not a valid indicator of important phenomena, and validation against traditional data is necessary to use ICD reliably.

In general, then, papers that rely on assumed validity make extremely strong assumptions about why their findings are likely to be valid. Researchers would be advised to think through their logic of inference carefully and consider whether their research can be reasonably justified through one of the first four approaches rather than appealing simply to the face validity of ICD.

\section{Measurement}

In addition to the issues about making inferences from the sample themselves, researchers using ICD also need to consider measurement.

\section{Inferring Attitudes from Behavior}

Survey research generally gathers a large quantity of systematic data about respondents' attitudes, but has relatively limited directly observed behavioral data (vote validation is a notable exception in electoral research). With ICD, the situation is usually reversed: there is large quantities of nonsystematic behavioral data with little systematic attitudinal data. The issue for analyzing ICD is therefore how to interpret behaviors. 
One example of this problem is Google Trends data. Researchers observe normalized counts of searches for a given term, but have to assume the reasons why these people searched for the terms they did. Are people searching for "Trump" because they plan to vote for Donald Trump in the Republican primary, because they want to find negative information about him, or because they plan to stay at a Trump hotel? With Google Trends data it is possible to see what other terms are being combined with a search term which can help to disambiguate these meanings (Mellon, 2013a), but the meaning of behavioral data will often be ambiguous.

\section{Non-behavior and self-selection}

While any survey response is technically behavioral, the fact that the survey respondents are proactively collected by the researcher reduces the impact of self-selection. By contrast, ICD events are proactively generated by the research subjects themselves. Consequently, we only observe any behavior (such as tweeting, posting, or even reading) for people who are sufficiently motivated to take this action. Making inferences about what people in general think on the basis of the actions of the most motivated can therefore be potentially misleading. Consequently researchers need to make explicit how they are considering the large number of potential subjects in their study who did not take an action. While there may be unprecedented numbers of people searching for Donald Trump, the vast majority of people on any given day will not be doing so. Researchers need to consider whether it is valid to make inferences about people who did not take an action on the basis of the behavior of those people who did take an action.

\section{Artifacts of the platform}

Another potential problem with ICD are the extent to which certain behaviors are encouraged or even automated by the platform itself. Google auto-completes searches with suggestions, Facebook and Twitter suggest possible people to connect with, and change.org emails users with suggested petitions to sign. Even email clients will automatically include all previous recipients in a message when a user clicks "reply-all". Consequently it is easy for research to conflate the design of the platform itself with the behavior of users on that platform.

This problem has become more acute with the introduction of algorithmic timelines on several platforms. This means that users are exposed to content on the basis of a proprietary algorithm rather than chronologically. This has led to controversy when the Facebook algorithm was alleged to reduce the visibility of conservative leaning news outlets (LaCapria, 2016) and further highlights the role that a platform's algorithms play in the behavior of its users.

\section{Spam and fake data}

Since the collection of ICD is generally not determined by the researcher, there are fewer protections against fake or duplicate information. Twitter and Facebook are both frequently targeted by advertising bots. These may even end up contaminating political data if they make use of popular hashtags, or retweet political information to help hide their tracks. Researchers should proactively look for this kind of contamination when using social media data.

\section{Doing it Right: Two Case Studies}

This chapter has focused on the pitfalls of ICD analysis. However, ICD can be used to conduct novel and important analyses. This section briefly describes two such examples. 


\section{Estimating ideology from Twitter}

The first paper I discuss is Pablo Barberás analysis of the interactions of politicians and citizens on Twitter (Barbera, 2014). Barberá aims to makes inferences about the ideology of elite political actors (politicians, media outlets and think tanks) based on the composition of users they interact with and who follow them (assuming that people choose to interact with people who are ideologically similar to them). While legislators have long been classified on the basis of ideology, Barberá points out that other types of political actors have generally not been able to be rated on the same scale, so developing a method that can estimate ideology for any political actor (providing they are on Twitter) is a useful additional tool.

Barberá correctly samples at the level of the user by first choosing several hundred political Twitter accounts in each of the countries in the study. He then downloads the information for each Twitter user who follows at least one of these target accounts. These users then allow the position of the elites and general users to be simultaneously estimated on the basis of their connections to each other. Barberá uses the logic of validation at both the standard user and elite level. For normal users he validates the ideal point estimates against matched data on users' campaign contributions and party registration. At the elite level he validates the ideal point estimates against DW-nominate scores in the US and expert survey measures of ideology in other countries. Barbera also accounts for potential contamination of measurement by spam on Twitter by excluding accounts with low levels of activity.

This analysis exemplifies good practice for analyzing ICD by combining ICD with traditional data sources, appropriately choosing the unit of analysis, and accounting for potential biases in the data caused by the platform.

\section{Scraping Social Media to Study Chinese Internet Censorship}

The second example of high quality ICD analysis is King et al.'s analysis of the Chinese government's censorship of Internet users expressing opinions (King, Pan, \& Roberts, 2013). The researchers focus on manual censorship of social media posts in China (as opposed to keyword blocking or the Chinese firewall). Chinese social media companies keep large staffs of censors to read through every post on their site and remove any offending content. The researchers posit two possible aims of a censorship program: suppressing criticism or preventing collective action.

They conduct their analysis by automatically scraping social media posts from 1,400 different social media services in China as they were posted. They argue that this gives a reasonable picture of precensored content, because most censoring of social media is manual rather than automatic (due to users' ability to sidestep keyword blocks and other automated tools). They then rescrape these original posts frequently to see whether they have been censored. Using this method, they find that $13 \%$ of all social media posts were censored. They organize the analysis around bursts of social media activity (periods where the number of posts is more than three standard deviations higher than the rest of the period) and then identify the event that led to the burst based on the content of the posts that appear at that time. They then categorize these events according to: collective action potential, criticism of censors, pornography, government policies and other news. Collective action potential is defined as events involving protest or crowd formation, relate to individuals who have organized such events in the past or relate to nationalism (which has incited much protest and collective action in the past).

The analysis leads to the insight that the Chinese censors are not primarily trying to suppress criticism of the regime, but instead focus on preventing collective action against the regime through censorship. Social media posts that relate to attempts to mobilize people are censored, but mere criticism without a call to action is allowed to stand. Interestingly even collective action in favor of the government is 
heavily censored, providing further evidence that it is the mobilization itself that the regime tries to avoid.

The researchers carefully validate their coding categories by manually reading large numbers of them and by using automated clustering methods to summarize the content of their categories to look for miscoding. The researchers also precisely outline what they are making inferences about. At the most direct level, they argue that their analysis demonstrates the revealed preferences of the Chinese censors. They further infer that these revealed preferences are likely to partially reflect the interests of the Chinese government itself, while acknowledging that these preferences will not be completely consistent across the different levels of the regime and that the match between censoring behavior and preferences will not be exact. Researchers also sensibly limit their claims to freedom of expression on the Internet in China, warning that "we offer little evidence here of connections between what we learn in social media and ...other types of human expression in China". This approach follows the logic of limiting the inference to the sampled population, focusing primarily on the behavior of the Chinese regime online.

This paper highlights the unique advantages of ICD in tackling a research question which would have been very difficult to examine using standard sources such as media coding, interviews or survey analysis, which would either be impossible to conduct or would be highly biased in the context of the Chinese regime. The paper uses ICD not because it is a convenient source (the amount of work to collect the posts likely exceeded that of many traditional data collection efforts), but because it is the most relevant source to understand an important issue in political science.

\section{Conclusions}

This chapter has outlined the sources of incidentally collected data that have been used in public opinion and elections research. The nature of the data necessitates a careful consideration of what population is being researched and how the behavior on these platforms can be interpreted.

While ICD sources are highly varied, researchers would be advised to consider the following questions when deciding whether to use ICD in their research. The first question is whether the research question is best answered using ICD or is there another data source that would work better? The second question researchers should ask is how the ICD they are using was collected and make sure that this process is accounted for in the analysis process. Finally, researchers should ask what population they want to make inferences about and whether the data they have is structured appropriately to make these inferences.

While this chapter has emphasized the limitations of ICD in political analysis, this should not distract from the substantial research possibilities that ICD opens up. There are very limited possibilities for collecting large scale network data outside of ICD, for instance. It fact it is precisely because of the increasing use of ICD in political science, that it is important for researchers to understand how to best make use of these data sources and understand their limitations. 


\section{Bibliography}

Adi, A., Erickson, K., \& Lilleker, D. G. (2013). Elite tweets: Analyzing the twitter communication patterns of Labour party peers in the House of Lords. Policy and Internet, 6(1), 1-27. http://doi.org/10.1002/1944-2866.POI350

Anderegg, W. R. L., \& Goldsmith, G. R. (2014). Public interest in climate change over the past decade and the effects of the "climategate" media event. Environmental Research Letters, 9(5), 054005. http://doi.org/10.1088/1748-9326/9/5/054005

Barbera, P. (2014). Birds of the Same Feather Tweet Together: Bayesian Ideal Point Estimation Using Twitter Data. Political Analysis, 23(1), 76-91. http://doi.org/10.1093/pan/mpu011

Bond, R. M., Fariss, C. J., Jones, J. J., Kramer, A. D. I., Marlow, C., Settle, J. E., \& Fowler, J. H. (2012). A 61-million-person experiment in social influence and political mobilization. Nature, 489(7415), 295-8. http://doi.org/10.1038/nature11421

Boyadjian, J., \& Neihouser, M. (2014). Why and How to Create a Panel of Twitter Users. In M. M. Skoric, P. Parycek, \& M. Sachs (Eds.), CeDEM Asia 2014: Conference for E-Democracy an Open Government. MV-Verlag. Retrieved from https://books.google.com/books?hl=en\&lr=\&id=plqlCgAAQBAJ\&pgis=1

Boyd, D., \& Crawford, K. (2011). Six Provocations for Big Data. SSRN Electronic Journal. http://doi.org/10.2139/ssrn.1926431

Bruner, J. (2013). Tweets loud and quiet. Retrieved February 29, 2016, from http://radar.oreilly.com/2013/12/tweets-loud-and-quiet.html

Bruns, A., \& Highfield, T. (2013). POLITICAL NETWORKS ON TWITTER. Information, Communication \& Society, 16(5), 667-691. http://doi.org/10.1080/1369118X.2013.782328

Burnap, P., Gibson, R., Sloan, L., Southern, R., \& Williams, M. (2015). 140 characters to victory?: Using Twitter to predict the UK 2015 General Election. Electoral Studies. http://doi.org/10.1016/j.electstud.2015.11.017

Caldarelli, G., Chessa, A., Pammolli, F., Pompa, G., Puliga, M., Riccaboni, M., ... Benito, R. (2014). A Multi-Level Geographical Study of Italian Political Elections from Twitter Data. PLoS ONE, 9(5), e95809. http://doi.org/10.1371/journal.pone.0095809

Camaj, L., \& Santana, A. D. (2015). Political Deliberation on Facebook during Electoral Campaigns: Exploring the Relevance of Moderator's Technical Role and Political Ideology. Journal of Information Technology \& Politics, 12(4), 325-341. http://doi.org/10.1080/19331681.2015.1100224

Choy, M., Cheong, M., Laik, M. N., \& Shung, K. P. (2012). US Presidential Election 2012 Prediction using Census Corrected Twitter Model. Applications; Computers and Society. Retrieved from http://arxiv.org/abs/1211.0938

Christensen, C. (2013). WAVE-RIDING AND HASHTAG-JUMPING. Information, Communication \& Society, 16(5), 646-666. http://doi.org/10.1080/1369118X.2013.783609

Cook, J. M. (2015). Are American Politicians as Partisan Online as They are Offline? Twitter Networks in the U. S. Senate and Maine State Legislature. Policy \& Internet, 8(1). http://doi.org/10.1002/poi3.109

Digrazia, J., McKelvey, K., Bollen, J., \& Rojas, F. (2013). More tweets, more votes: social media as a quantitative indicator of political behavior. PloS One, 8(11), e79449. http://doi.org/10.1371/journal.pone.0079449

Ellis, C., Swearingen, C., \& Ripberger, J. T. (2011). Examining the Impact of Public Attention on Fundraising in U.S. Senate Elections. Retrieved from http://papers.ssrn.com/sol3/papers.cfm?abstract_id=1901704

Enli, G. S., \& Skogerbø, E. (2013). PERSONALIZED CAMPAIGNS IN PARTY-CENTRED POLITICS. Information, Communication \& Society, 16(5), 757-774. http://doi.org/10.1080/1369118X.2013.782330

Fisher, S. D., \& Lewis-Beck, M. S. (2015). Forecasting the 2015 British general election: The 1992 debacle all over again? Electoral Studies. http://doi.org/10.1016/j.electstud.2015.11.016

Garzia, D., \& Marschall, S. (2012). Voting Advice Applications under review: the state of research. International Journal of Electronic Governance, 5(3/4), 203. http://doi.org/10.1504/IJEG.2012.051309 
Gayo-Avello, D. (2012). "I Wanted to Predict Elections with Twitter and all I got was this Lousy Paper" -- A Balanced Survey on Election Prediction using Twitter Data, 13. Computers and Society; Computation and Language; Physics and Society. Retrieved from http://arxiv.org/abs/1204.6441

Gayo-Avello, D., Metaxas, P. T., \& Mustafaraj, E. (2011). Limits of Electoral Predictions using Twitter. Association for the Advancement of Artificial Intelligence. Retrieved from http://digibuo.uniovi.es/dspace/handle/10651/11899

Gibson, R., \& Ward, S. (2003). Letting the daylight in? Australian parties' use of the World Wide Web at the state and territory level. In R. Gibson, P. Nixon, \& S. Ward (Eds.), Political Parties and the Internet: Net Gain? (pp. 161-174). Routledge. Retrieved from https://books.google.com/books?hl=en\&lr=\&id=g_yBAgAAQBAJ\&pgis=1

Graefe, A., \& Armstrong, J. S. (2012). Predicting elections from the most important issue: A test of the take-the-best heuristic. Journal of Behavioral Decision Making, 25(1), 41-48. http://doi.org/10.1002/bdm.710

Granka, L. A. (2010). Measuring Agenda Setting with Online Search Traffic: Influences of Online and Traditional Media. Retrieved from http://papers.ssrn.com/sol3/papers.cfm?abstract_id=1658172

Gruzd, A. (2012). Investigating Political Polarization on Twitter: A Canadian Perspective. Internet, Politics, Policy 2012: Big Data, Big Challenges?, 6(1), 1-11. Retrieved from http://microsites.oii.ox.ac.uk/ipp2012/sites/microsites.oii.ox.ac.uk.ipp2012/files/Gruzd2012_OII _IPP_Political_Polarization_Aug_15_2012.pdf

Hollway, J., \& Mellon, J. (2014). Leading the Conversation: Comparing State Department Communication Networks Under Rogers and Kissinger. Retrieved from http://papers.ssrn.com/abstract=2443042

Jensen, M. J., \& Anstead, N. (2013). Psephological investigations: Tweets, votes, and unknown unknowns in the republican nomination process. Policy and Internet, 5(2), 161-182. http://doi.org/10.1002/1944-2866.POI329

Jungherr, A. (2014). The Logic of Political Coverage on Twitter: Temporal Dynamics and Content. Journal of Communication, 64(2), 239-259. http://doi.org/10.1111/jcom.12087

Jungherr, A., Jurgens, P., \& Schoen, H. (2011). Why the Pirate Party Won the German Election of 2009 or The Trouble With Predictions: A Response to Tumasjan, A., Sprenger, T. O., Sander, P. G., \& Welpe, I. M. "Predicting Elections With Twitter: What 140 Characters Reveal About Political Sentiment." Social Science Computer Review, 30(2), 229-234. http://doi.org/10.1177/0894439311404119

King, G., Pan, J., \& Roberts, M. (2013). How Censorship in China Allows Government Criticism but Silences Collective Expression. American Political Science Review, 107(917), 326-343. http://doi.org/10.1017/S0003055413000014

Koehler-Derrick, G. (2013). Quantifying Anecdotes: Google Search Data and Political Developments in Egypt. PS: Political Science \& Politics, 46(02), 291-298. http://doi.org/10.1017/S1049096513000267

LaCapria, K. (2016). The Algorithm Is Gonna Get You.

Larsson, A. O., \& Moe, H. (2011). Studying political microblogging: Twitter users in the 2010 Swedish election campaign. New Media \& Society, 14(5), 729-747. http://doi.org/10.1177/1461444811422894

Marchetti-Bowick, M., \& Chambers, N. (2012). Learning for microblogs with distant supervision: political forecasting with Twitter, 603-612. Retrieved from http://dl.acm.org/citation.cfm?id=2380816.2380890

McKelvey, K., DiGrazia, J., \& Rojas, F. (2014). Twitter publics: how online political communities signaled electoral outcomes in the 2010 US house election. Information, Communication \& Society, 17(4), 436-450. http://doi.org/10.1080/1369118X.2014.892149

Mellon, J. (2013a). Internet Search Data and Issue Salience: The Properties of Google Trends as a Measure of Issue Salience. Journal of Elections, Public Opinion \& Parties. Retrieved from http://www.tandfonline.com/doi/abs/10.1080/17457289.2013.846346\#.VtSg2tByYZw

Mellon, J. (2013b). Where and When Can We Use Google Trends to Measure Issue Salience? PS: Political Science \& Politics, 46(02), 280-290. http://doi.org/10.1017/S1049096513000279 
Mellon, J., \& Prosser, C. (2016). Twitter and Facebook are not representative of the General Population: Political Attitudes and Demographics of Social Media users. SSRN Electronic Journal.

Mellon, J., Sjoberg, F. M., \& Peixoto, T. (2016a). Connective Action: The Prevalence and Effects of Large Scale Transnational Activism. SSRN Electronic Journal.

Mellon, J., Sjoberg, F. M., \& Peixoto, T. (2016b). Connective Action: The Prevalence and Effects of Large Scale Transnational Activism. World Bank Working Paper.

Metaxas, P. T., Mustafaraj, E., \& Gayo-Avello, D. (2011). How (Not) to Predict Elections. In 2011 IEEE Third Int'l Conference on Privacy, Security, Risk and Trust and 2011 IEEE Third Int'l Conference on Social Computing (pp. 165-171). IEEE. http://doi.org/10.1109/PASSAT/SocialCom.2011.98

Mokrzycki, M., Keeter, S., \& Kennedy, C. (2009). Cell-Phone-Only Voters in the 2008 Exit Poll and Implications for Future Noncoverage Bias. Public Opinion Quarterly, 73(5), 845-865. http://doi.org/10.1093/poq/nfp081

Monroe, B. L. (2012). The Five Vs of Big Data Political Science: Introduction to the Virtual Issue on Big Data in Political Science. Political Analysis, (2008), 1-9.

O’Connor, B., Balasubramanyan, R., Routledge, B. R., \& Smith, N. a. (2010). From tweets to polls: Linking text sentiment to public opinion time series. From Tweets to Polls: Linking Text Sentiment to Public Opinion Time Series, 122-129. http://doi.org/citeulike-article-id:7044833

Pelc, K. J. (2013). Googling the WTO: What Search-Engine Data Tell Us About the Political Economy of Institutions. International Organization, 67(03), 629-655. http://doi.org/10.1017/S0020818313000179

Ragas, M. W., \& Tran, H. (2013). Beyond Cognitions: A Longitudinal Study of Online Search Salience and Media Coverage of the President. Journalism \& Mass Communication Quarterly, 90(3), 478-499. http://doi.org/10.1177/1077699013493792

Raynauld, V., \& Greenberg, J. (2014). Tweet, Click, Vote: Twitter and the 2010 Ottawa Municipal Election. Journal of Information Technology \& Politics, 1681(May 2015), 140701133856000. http://doi.org/10.1080/19331681.2014.935840

Ripberger, J. T. (2011). Capturing Curiosity: Using Internet Search Trends to Measure Public Attentiveness. Policy Studies Journal, 39(2), 239-259. http://doi.org/10.1111/j.15410072.2011.00406.x

Sang, E. T. K., \& Bos, J. (2012). Predicting the 2011 dutch senate election results with Twitter, $53-$ 60. Retrieved from http://dl.acm.org/citation.cfm?id=2389969.2389976

Scharkow, M., \& Vogelgesang, J. (2011). Measuring the Public Agenda using Search Engine Queries. International Journal of Public Opinion Research, 23(1), 104-113. http://doi.org/10.1093/ijpor/edq048

Sjoberg, F. M., Mellon, J., \& Peixoto, T. (2015). The Effect of Government Responsiveness on Future Political Participation. SSRN Electronic Journal. http://doi.org/10.2139/ssrn.2570898

Stephens-Davidowitz, S. I. (2012). The Effects of Racial Animus on a Black Presidential Candidate: Using Google Search Data to Find What Surveys Miss. Harvard University Working Paper. Retrieved from http://papers.ssrn.com/sol3/papers.cfm?abstract_id=2050673

Sturgis, P., Baker, N., Mario Callegaro, Q., Stephen Fisher, G., Jane Green, P., Will Jennings, P., ... Smith, P. (2016). Report of the Inquiry into the 2015 British general election opinion polls Table of Contents. British Polling Council.

Tan, C., Niculae, V., Danescu-Niculescu-Mizil, C., \& Lee, L. (2016). Winning Arguments: Interaction Dynamics and Persuasion Strategies in Good-faith Online Discussions, 12. Computation and Language; Physics and Society. http://doi.org/10.1145/2872427.2883081

Tepper, F. (2014). Are Americans losing interest in global warming? Hardly. Christian Science Monitor. Retrieved from http://www.csmonitor.com/Science/2014/0522/Are-Americans-losinginterest-in-global-warming-Hardly.-video

Tumasjan, A., Sprenger, T. O., Sandner, P. G., \& Welpe, I. M. (2010). Predicting Elections with Twitter: What 140 Characters Reveal about Political Sentiment, 178-185.

Vaccari, C., Valeriani, A., Barberá, P., Bonneau, R., Jost, J. T., Nagler, J., \& Tucker, J. A. (2013). Social media and political communication: a survey of twitter users during the 2013 italian general election. Rivista Italiana Di Scienza Politica. Il Mulino. Retrieved from 
https://dialnet.unirioja.es/servlet/articulo?codigo $=4640188$

Vraga, E. K., Anderson, A. A., Kotcher, J. E., \& Maibach, E. W. (2015). Issue-Specific Engagement: How Facebook Contributes to Opinion Leadership and Efficacy on Energy and Climate Issues. Journal of Information Technology \& Politics, 12(April 2016), 200-218. http://doi.org/10.1080/19331681.2015.1034910

Wall, M., Krouwel, A., \& Vitiello, T. (2014). Do voters follow the recommendations of voter advice application websites? A study of the effects of kieskompas.nl on its users' vote choices in the 2010 Dutch legislative elections. Party Politics, 20(3), 416-428. http://doi.org/10.1177/1354068811436054

Ward, J. S., \& Barker, A. (2013). Undefined By Data: A Survey of Big Data Definitions, 2. Databases. Retrieved from http://arxiv.org/abs/1309.5821

Weeks, B., \& Southwell, B. (2010). The Symbiosis of News Coverage and Aggregate Online Search Behavior: Obama, Rumors, and Presidential Politics. Mass Communication and Society, 13(4), 341-360. http://doi.org/10.1080/15205430903470532

Wilde, G. R., \& Pope, K. L. (2012). Worldwide trends in fishing interest indicated by internet search volume. Fisheries Management and Ecology, n/a-n/a. http://doi.org/10.1111/fme.12009 